\title{
Heat Transfer Model of Casted Heat Exchanger in Summer Condition
}

\author{
Yu Jie ${ }^{1,2, a}$, Ni Weichen ${ }^{1,2, b}$ and You Shijun ${ }^{3, c}$ \\ ${ }^{1}$ School of Automation, Tianjin University of Technology, 300384, China \\ ${ }^{2}$ Tianjin Key laboratory for Control Theory and Applications in Complicated System, 300384, China \\ ${ }^{3}$ School of Environment Science and Technology, Tianjin University, 300072, China \\ ayujie_89@139.com, bvision.ni@163.com, cyousj@tju.edu.cn
}

Keywords: Seawater-source heat pump; Casted heat exchanger; Heat conduction; Natural convection.

\begin{abstract}
To overcome the disadvantages of the open loop seawater source heat pump (SWHP), a closed loop SWHP system with casted heat exchangers (CHEs) is presented in this paper. Consisting of closed-loop of pipes immersed in seawater, CHEs are devised for extraction or injection of thermal energy from/into the seawater. A mathematical model has been established and solved analytically to describe the heat transfer process of CHEs in summer. An experimental system has been built to simulate the heat transfer process. The experimental results show that the relative error of the temperature distributions along the CHEs between the experimental data and numerical simulation result is less than 5\%. As a result, the mathematical model can be applied to optimization analysis of the CHEs used for SWHP systems.
\end{abstract}

\section{Introduction}

Due to reduced energy consumption and maintenance costs, seawater source heat pump (SWHP) systems, which use seawater as a heat source/sink, have been gaining increasing popularity for space conditioning in buildings for coastal areas [1-2]. Tianjin is an important port in China and is rich in seawater. The geographical factors and recent energy policy provide convenient conditions for the application of SWHP project [3]. Recently, many researchers have carried out a great deal of research about SWHP systems. For instance, A. Aittomäki studied the possibility of using lake water as heat source for heat pump heating in cold climate [4]. O. Büyükalaca, F. Ekinci and T. Yilmaz investigated the Seyhan River and dam lake as heat source-sink for a heat pump [5]. Yu Jie researched the heat transfer process of the CHEs used for SWHP in icing and no-icing conditions in winter [6].SWHP is classified into open and closed loop SWHP systems according to the shape of the loop under the water [7-10]. Most researches about SWHP use the open loop system. But one of the biggest challenges of this system is scaling. The water used by the system needs to be recharged to the seawater, so the chemical method can't be applied. In addition, sea creatures in seawater would enter the SWHP system and the larvae and spores may grow in the pipeline so that seawater supply system can't be operated normally. So seawater must be treated before it entered the SWHP system. Thus the initial investment of the system was increased.

Therefore, for the purpose of overcoming the disadvantages of the open loop SWHP, a closed loop SWHP system with casted heat exchanger (CHE) is presented in this paper. The unit of the closed loop system doesn't contact with the seawater directly, so there is no scaling and breeding in this system. Moreover, because there is no need to overcome the resistance from the distribution point to the unit so that the energy consumption in the closed loop system is less than the open loop. And in the closed loop system, the heat exchanger can get more temperature difference between inlet and outlet fluid to reduce the water flow rate. In the present study, the mathematical model that described heat transfer process of the CHE in summer was established. And an experimental rig which simulated the heat transfer process of $\mathrm{CHE}$ was built to validate the mathematic model. 


\begin{tabular}{|c|c|c|c|}
\hline \multicolumn{4}{|c|}{ Nomenclature } \\
\hline & specific heat[J/kgK] & \multicolumn{2}{|c|}{ Greek symbols } \\
\hline$d$ & diameter $[\mathrm{m}]$ & $\lambda$ & thermal conductivity[W/mK] \\
\hline & Grashof number & $v$ & $\begin{array}{l}\text { kinetic viscosity coefficient } \\
{\left[\mathrm{m}^{2} / \mathrm{s}\right]}\end{array}$ \\
\hline & convection coefficient $\left[\mathrm{W} / \mathrm{m}^{2} \mathrm{~K}\right]$ & $\rho$ & $\operatorname{density}\left[\mathrm{kg} / \mathrm{m}^{3}\right]$ \\
\hline & Prandtl number & \multicolumn{2}{|c|}{ Subscripts } \\
\hline$Q$ & heat energy[W] & $\mathrm{f}$ & fluid \\
\hline & fouling coefficient $\left[\mathrm{m}^{2} \mathrm{~K} / \mathrm{W}\right]$ & $\mathrm{i}$ & i-th control volume \\
\hline & temperature[K] & in & inner pipe \\
\hline & velocity $[\mathrm{m} / \mathrm{s}]$ & out & outer pipe \\
\hline & control volume length[m] & $\mathrm{w}$ & pipe wall \\
\hline
\end{tabular}

\section{Mathematical modeling}

The schematic diagrams of a CHE control volume for heat transfer in summer are illustrated in Fig.1. The flow direction of the secondary refrigerant is also given in Fig.1.The CHE is divided into $\mathrm{N}$ control volumes equally along the flow direction. And the length of every control volume is $\Delta x$. The analysis of every control volume based on the energy balance is performed subject to the following assumptions [11]:

(1) Thermal properties of the pipe and seawater are constant.

(2) The temperature and flow rate of fluid in the pipe are uniform at any cross- section.

(3) The effect of the curve radius is neglected.

(4) The conductive heat transfer along the fluid channels is very small and therefore neglected.

(5) The model is in the steady state.

Model in summer. The heat transfer between the secondary refrigerant flowing in the CHE and the seawater outside the heat exchanger goes through three processes as follows:

(1) Convective heat transfer between the fluid inside the pipe and the inside wall of the pipe.

(2) Conductive heat transfer through the pipe wall.

(3) Convective heat transfer between the seawater and the outside wall of the pipe.

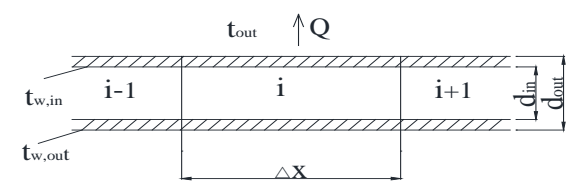

Fig.1 Schematic diagram of heat transfer in summer

The heat flux due can be written using the following equations:

$Q_{i}=\left(h_{\text {out }, w}+\frac{1}{r_{o}}\right) \pi d_{\text {out }} \Delta x\left(t_{\text {out }}-t_{w, \text { out }, i}\right)$.

where $r_{o}$ is the fouling coefficient, it's equal to $0.0006 \mathrm{~m}^{2} \cdot \mathrm{K} / \mathrm{W}$.

$\mathrm{Nu}=C\left(G r_{\text {out }} \cdot \mathrm{Pr}_{\text {out }}\right)^{n}$.

where $\mathrm{C}$ is equivalent to 0.48 and $\mathrm{n}$ is 0.25 according to the low flow rate of the seawater.

$Q_{i}=2 \pi \cdot \lambda_{w} \cdot \Delta x \cdot \frac{t_{w, \text { out }, i}-t_{w, i n, i}}{\ln \frac{d_{\text {out }}}{d_{\text {in }}}}$.

where $\lambda_{\mathrm{w}}$ is equal to $0.49 \mathrm{~W} / \mathrm{m} \cdot \mathrm{K}$.

$Q_{i}=h_{i n} \cdot \pi \cdot d_{i n} \cdot \Delta x \cdot\left(t_{w, i n, i}-t_{f, i}\right)$. 


$$
h_{\text {in }}=\frac{0.023 \operatorname{Re}_{i n}^{0.8} \cdot \operatorname{Pr}_{i n}^{n} \cdot \lambda_{w}}{d_{\text {in }}} .
$$

where $\mathrm{n}=0.3$ for cooling.

$$
\begin{aligned}
& \operatorname{Re}_{i n}=\frac{u_{\text {in }} \cdot d_{\text {in }}}{v_{\text {in }}} . \\
& Q_{i}=\frac{\pi}{4} \cdot d_{\text {in }}^{2} \cdot v_{\text {in }} \cdot \rho_{\text {in }} \cdot c_{p, \text { in }} \cdot \frac{\mathrm{t}_{f, i+1}-\mathrm{t}_{f, i-1}}{2} .
\end{aligned}
$$

\section{Experiment results and discussion}

Experiment system. In order to validate the mathematic model established above, an experimental rig which simulated the heat transfer process of CHE was built, as shown in Fig.2. The maximum flow rate of the circulating pumps is $6 \mathrm{~m}^{3} / \mathrm{h}$. The CHE consists of a high-density polyethylene pipe(HDPE) which has $200 \mathrm{~m}$ length and 32mm outer diameter submersed in a water reservoir at $3 \mathrm{~m}$. The model of the casted heat exchanger is shown in Fig.3.

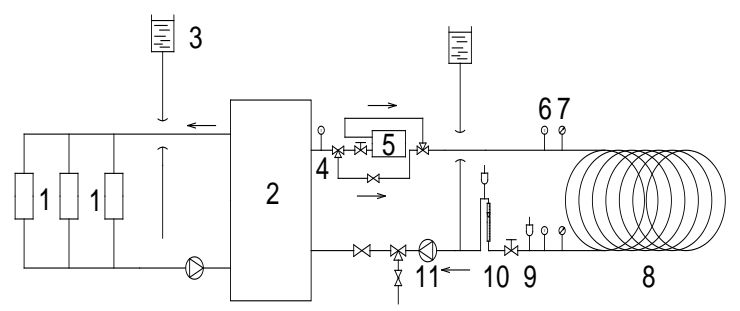

Fig.2 Flow diagram of experimental system in summer

(1) fan coil, (2) heat pump unit, (3)expansion tank, (4,6) stem thermometer,(5) fan coil pipe, (7) pressure meter,

(8) casted heat exchanger, (9) automatic exhaust valve, (10) float-flow-meter,(11) pump

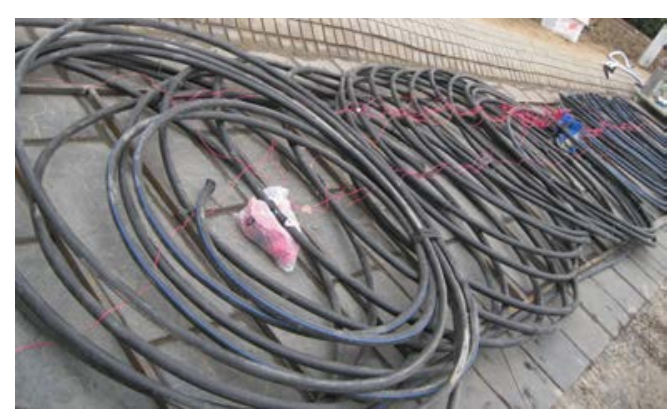

Fig.3 The configuration view of casted heat exchanger

Experiment validation. The parameters correlated with the model validation in the experimental system are listed in Tables 1 and 2.

For the CHE model, the test may be performed by the comparison on the outlet temperature of CHE between the experimental value and the calculated value by the model under given inlet temperature and flow rate with and without submerged pump in the water reservoir. In order to validate the mathematical model developed above, an experimental test is undertaken in the experimental system shown in Fig.2. The test system includes the testing of temperature, glycol solution flow rate and inlet and outlet pressures of the CHE. The temperature test is performed automatically by T-type thermocouple using a Fluent Data Acquisition device. The flow rate is tested by a float-flow-meter. 
Table 1 Properties of water-ethylene glycol mixture

\begin{tabular}{lll}
\hline $10 \%$ by weight & Unit & Value \\
\hline Density & $\mathrm{kg} / \mathrm{m}^{3}$ & 1018 \\
Specific heat & $\mathrm{kJ} / \mathrm{kg} \cdot \mathrm{K}$ & 3.937 \\
Kinematic viscosity & $10^{-5} \mathrm{~m}^{2} / \mathrm{s}$ & 2.04 \\
Pr & - & 16.0 \\
\hline \multicolumn{3}{c}{ Properties of seawater } \\
\hline $0^{\circ} \mathrm{C}$ & Unit & Value \\
\hline Kinematic viscosity & $10^{-6} \mathrm{~m}^{2} / \mathrm{s}$ & 1.5 \\
$\beta$ & $10^{-5} \mathrm{~K}^{-1}$ & 8.4 \\
$\operatorname{Pr}$ & - & 11.6 \\
\hline
\end{tabular}

Results and discussion. Under different ethylene glycol solution flow, while the ethylene glycol solution inlet temperature is constant, the calculated ethylene glycol solution outlet temperature and corresponding test date in summer with and without submerged pump is compared. The results are shown in Fig.4. It can be seen from the picture (a) that without the submerged pump, while the flow rate at $1100 \mathrm{~L} / \mathrm{h}$, the relative error is more than $5 \%$, which is not acceptable in engineering application. But from the picture (b), the conclusion can be drawn that the largest relative error is less than $5 \%$, which is acceptable. Simulation shows great agreement with the experimental data. This means the mathematical model in summer developed above can simulate effectively the heat transfer process of CHE.

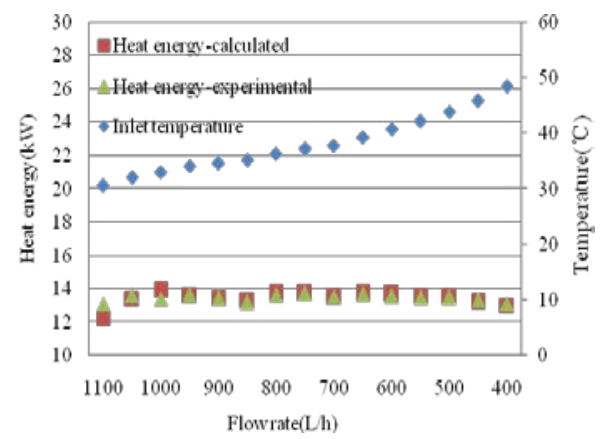

(a)without submerged pump

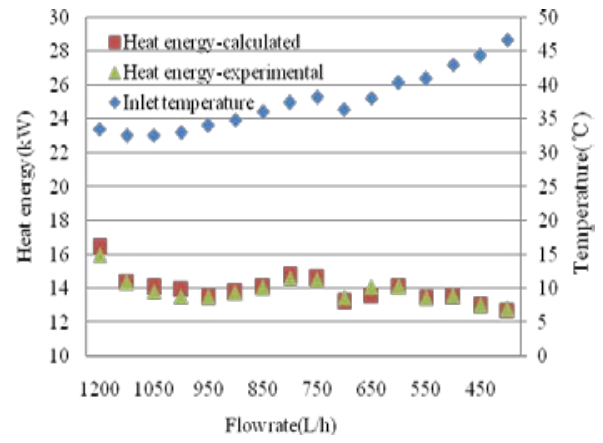

(b)with submerged pump

Fig.4 Comparison of the ethylene glycol solution outlet temperature between simulation and test in summer

\section{Conclusions}

This paper presented the mathematical model of CHE in summer based on energy balance equation. The model was validated by an experiment system. The following conclusions are achieved:

(1) The pipe length, flow rate and seawater temperature have been used in computer simulation and the results were satisfactory. As seen in Fig. 4, the temperature distributions along the CHE of the simulation are very close to the temperatures measured from the experimental work. The relative error is less than $5 \%$, which is acceptable in engineering application.

(2) Study demonstrates that the use of ocean thermal energy in Tianjin shows a promising prospect in the near future and has great potential for development in coastal cities in China.

\section{References}

[1] V.R. Tarnawski, W.H. Leong, T. Momose, Y. Hamada, Analysis of ground source heat pumps with horizontal ground heat exchangers for northern Japan, Renewable Energy 34 (2009) 127-134. 
[2] Young-hak Song, Yasunori Akashi, Effects of utilizing seawater as a cooling source system in a commercial complex, Energy and Buildings 39 (2007) 1080-1087.

[3] Xiao Chen, Guoqiang Zhang, Jianguo Peng, Xuanjun Lin, The performance of an open-loop lake water heat pump system in south China, Applied Thermal Engineering 26 (2006) 2255-2261.

[4] A. Aittomäki, Lakes as a heat source in cold climate, Proceedings of International Congress of Refrigeration, USA Washington, 2003.

[5] O. Büyükalaca, F. Ekinci, T. Yilmaz, Experimental investigation of Seyhan River and dam lake as heat source-sink for a heat pump, Energy 28 (2003) 157-169.

[6] Jie Yu, Huan Zhang, Shijun You, Heat Transfer Analysis and Experimental Verification of Casted Heat Exchanger in non-icing and icing conditions in Winter, Renewable Energy 41 (2012) 39-43.

[7] Information on http://www.friotherm.com/downloads/vaertan_e008_uk.pdf>.

[8] Kavanaugh SP, Design considerations for ground and water source heat pumps in southern climates, ASHRAE Trans 95 (1) (1989) 1139-49.

[9] Parsons, Robert, ASHRAE Handbook-Heating, Ventilating, and Air-Conditioning Systems and Applications, ASHRAE Inc., 1987.

[10]Parsons, Robert, ASHRAE Handbook- Systems, ASHRAE Inc., 1980.

[11] Tao Wenshuan. Numerical Heat Transfer(Second Edition) [M]. Xi’an Jiaotong University Press, Xi’an, China, 2001 (in Chinese). 